\title{
Effects of Perimeter Trap Crop Pollen on Reproduction in Butternut Squash (Cucurbita moschata)
}

\author{
Kristen R. Hladun \\ Plant Biology Program, Department of Plant, Soil, and Insect Sciences, \\ University of Massachusetts, Amherst, MA 01003
}

Lynn S. Adler ${ }^{1}$

Department of Plant, Soil, and Insect Sciences and Graduate Program in Organismic and Evolutionary Biology, University of Massachusetts, Amherst, 209E Fernald Hall, 270 Stockbridge Road, Amherst, MA 01003

Additional index words. blue hubbard squash, Cucurbita maxima, butternut squash, Cucurbita moschata, heterospecific pollen transfer, perimeter trap cropping

\begin{abstract}
Perimeter trap cropping (PTC) uses an attractive crop to concentrate pests at borders and reduce pesticide use while maintaining yield. A possible disadvantage of PTC could be pollen flow between border and main crops that are not interfertile. The effects of pollen composition and amount on seed and fruit production were investigated between a main crop species, butternut squash (Cucurbita moschata Duch. ex Poir), and a PTC species, blue hubbard ( $C$. maxima Duch.). Butternut squash plants were hand pollinated in the greenhouse with three pollen composition treatments crossed with four pollen amounts. Pure butternut squash pollen and mixed pollen produced more seeds per fruit and heavier seeds than pure blue hubbard pollen, revealing some incompatibility between butternut and blue hubbard. Saturating pollen amounts produced up to six times more seeds than lower pollen amounts. Pollen composition did not influence fruit set or fruit weight, which are of central importance for crop yield. This study suggests that pollen flow between blue hubbard borders and butternut squash should not interfere with crop production as long as sufficient conspecific pollen is deposited on stigmas.
\end{abstract}

Perimeter trap cropping (PTC) is an effective method of integrated pest management to control herbivores in cucurbit crops (Boucher and Durgy, 2004). Trap crops that are attractive to herbivores are planted around the main crop, concentrating pests at borders. Although PTC has the advantage of reducing pesticide use (Boucher and Durgy, 2004), the close proximity of PTC and main crops may increase heterospecific pollen transfer through shared pollinators. Pollen transfer between incompatible species can interfere with fertilization (Heinrich, 1981; Waser and Fugate, 1986) and thereby reduce fruit and seed production. Currently, there are no investigations of the potential for PTC

Received for publication 19 June 2007. Accepted for publication 16 Sept. 2007

This work was supported by the Plant Biology program at the University of Massachusetts at Amherst, a Constantine J. Gilgut Fellowship (KRH), a Davis and Delisle research grant (KRH), and a USDA CSREES Regional Integrated Pest Management grant (LSA).

We thank T.H. Boyle, J. Elkinton, and three anonymous reviewers for providing valuable comments on the manuscript. We also thank M. Messer, K. Bouley, T. Beauchesne, and C. Joyner for their help in the greenhouse; R. Hazzard and A. Cavanagh for advice on butternut; and R. Mullins for help with pollen measurements.

${ }^{1}$ To whom reprint requests should be addressed; e-mail lsadler@ent.umass.edu pollen interference to influence main crop yield.

Blue hubbard squash (Cucurbita maxima) is an effective PTC for the main crop, butternut squash ( $C$. moschata), because it is an attractive food source for a major cucurbit pest, the striped cucumber beetle (Acalymma vittatum F.) (Andersen and Metcalf, 1987; Boucher and Durgy, 2004). Blue hubbard produces more cucurbitacins and higher floral volatiles than butternut squash (Andersen and Metcalf, 1987), making it a preferred food source for several cucumber beetle species (Andersen and Metcalf, 1987; Fronk and Slater, 1956; McGrath, 2002).

Pollen flow between blue hubbard and butternut squash could interfere with pollination. Blue hubbard can cross with butternut squash, but the resulting fruits contain a high proportion of nonviable seeds (Whitaker and Bemis, 1964; Whitaker and Bohn, 1950; Whitaker and Davis, 1962), suggesting that pollen transfer between these two species may reduce crop yield. Squash bees (Peponapis spp.) transfer pollen between wild and domesticated Cucurbita species (Hurd et al., 1971; Kirkpatrick and Wilson, 1988) and thus may facilitate pollen transfer between cucurbit PTC and main crops. In a recent PTC study on butternut squash at 21 farms in western Massachusetts, squash bees (Peponapis pruinosa Say) constituted over onethird of pollinator visits to both blue hubbard and butternut squash (Cavanagh et al., unpublished data). Squash bees are also the main pollinators of Cucurbita crops in Maryland, Virginia, and West Virginia (Shuler et al., 2005). The first objective of this study was to examine the impact of conspecific, heterospecific, and mixed pollen transfer between blue hubbard and butternut squash on fruit and seed production.

Crop yield may be influenced by pollen amount as well as composition. Pollen deposition can limit reproduction in many cucurbits (Robinson and Decker-Walters, 1997). Low pollen deposition can result in lighter fruits or fruit abortion (Stanghellini et al., 1997; Stephenson et al., 1988; Walters and Taylor, 2006). Although fruit number and size were pollen-limited in a field study with C. moschata (Walters and Taylor, 2006), the pollen requirements of this species are unknown. The second objective of this study was to determine how pollen amount influenced butternut fruit and seed production.

\section{Materials and Methods}

Experimental design. This experiment was conducted at the University of Massachusetts at Amherst greenhouses from February through Aug. 2005. On 16 Feb., 240 butternut squash plants were planted (cultivar 'Waltham Butternut'; Johnny's Selected Seeds, Winslow, ME) and transplanted after 1 month to $22-\mathrm{L}$ pots containing Metromix 360 soil (The Scotts Co., Marysville, $\mathrm{OH}$ ) with $9.5 \mathrm{~g}$ per pot of slow-release fertilizer (Osmocote 14N-4.2P-11.6K; Scotts-Sierra Horticulture Products Co., Marysville, $\mathrm{OH}$ ). Twenty blue hubbard plants were grown as pollen sources.

The experiment had 12 treatment combinations with 20 replicates each for 240 plants total. Butternut squash were randomly assigned to three pollen composition treatments (butternut pollen, blue hubbard pollen, or mixed pollen) crossed with four pollen amounts [low (two applications), medium (four applications), high (six applications) and saturation]. In the low, medium, and high treatments, pollen was applied to stigmas using a thin wire applicator (Impex Systems Group, Miami, FL) with a $1-\mathrm{mm}$ diameter. One application contained $109 \pm 8$ butternut pollen grains $(X \pm S E, n=50)$ or $58 \pm 4$ blue hubbard grains $(n=40)$. Because the pollen requirements of $C$. moschata were not known, we chose these pollen amounts for two reasons. First, they closely approximate the pollen deposited by one, two, or three visits by a single squash bee ( 250 grains) or honeybee (Apis mellifera; 232 grains) to the congener $C$. pepo in a field study (Tepedino, 1981). Second, these amounts are comparable to those used in previous studies examining effects of pollen load on fruit maturation in C. pepo (Winsor et al., 1987). For the saturation treatment, pollen was applied to one stigma lobe using a paintbrush depositing an average of $4088 \pm 711$ butternut grains $(\mathrm{n}=10)$ or $2651 \pm 657$ blue hubbard grains $(n=8)$. Although butternut stigmas have three lobes, only one lobe was 
covered because this applied nearly an order of magnitude more pollen than the next highest treatment and nearly 40 times more pollen than the maximum seed production (Fig. 1). The differences in the number of pollen grains applied in the blue hubbard compared with butternut treatments were likely the result of the larger size of blue hubbard pollen grains (butternut 130.15 \pm $0.87 \mu \mathrm{m}$, blue hubbard $150.35 \pm 1.78 \mu \mathrm{m}, \mathrm{n}=$ 20 grains, $P<0.0001)$. Although different pollen amounts may introduce a treatment bias in terms of pollen number, field pollen deposition per stigma area by bees may also be lower for blue hubbard compared with butternut as a result of pollen size. Thus, our experimental treatments control for pollen deposition area rather than number.
Treatments began on 2 May 2005 and continued until 29 July 2005. Butternut and blue hubbard squash are both monoecious cucurbits and produce actinomorphic, selfcompatible unisexual flowers that last a single day. Three newly opened butternut and blue hubbard staminate flowers were collected between 0600 and 0700 HR every morning to ensure pollen freshness. Applicators and paintbrushes were cleaned with $100 \%$ ethanol between applications to prevent contamination. Up to two flowers were pollinated per plant. We concentrated our efforts on treating more plants rather than more flowers per plant because plant is the unit of replication and so pollinating additional flowers per plant would not increase our statistical power to test treatment effects.
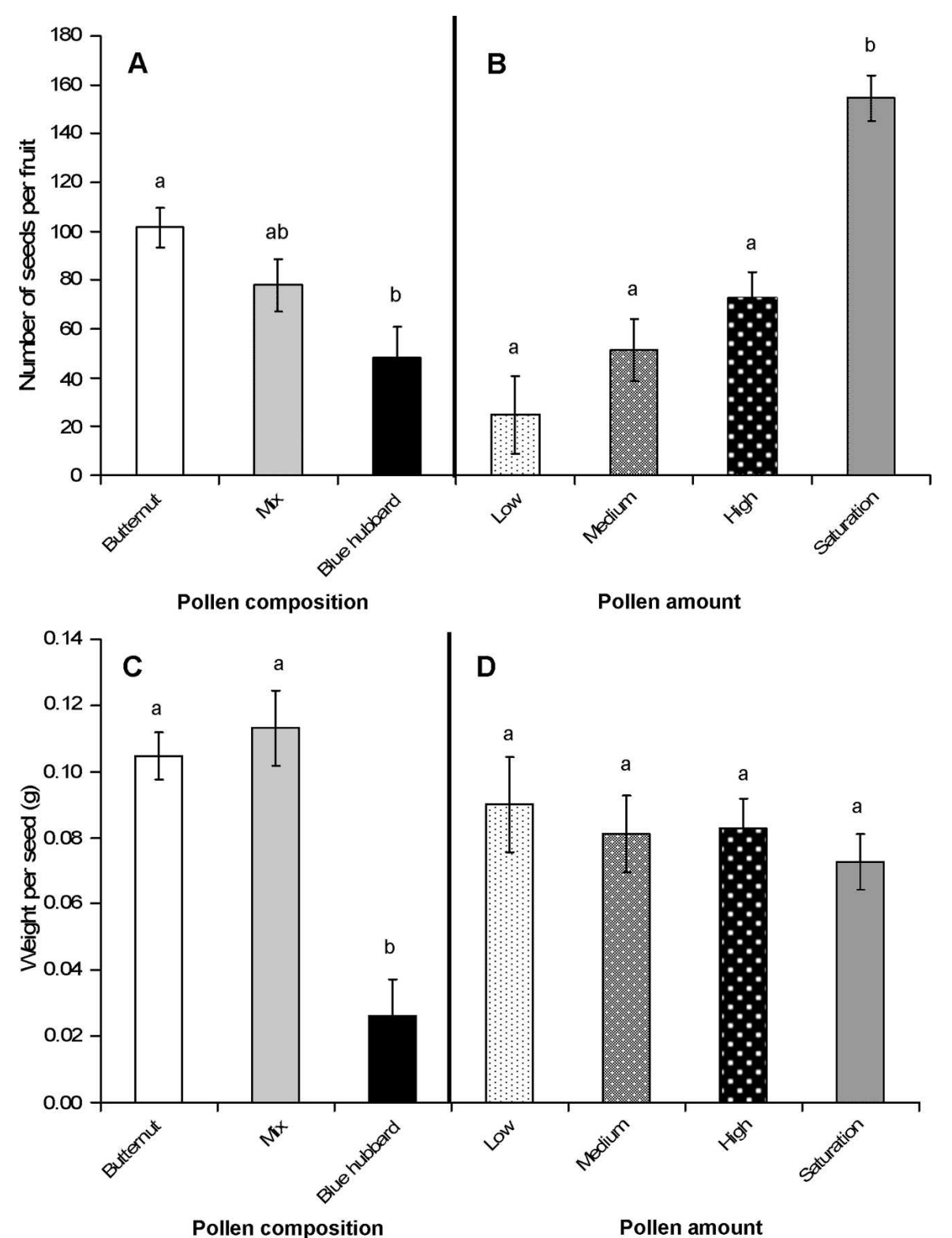

Fig. 1. Influence of pollen composition (pure butternut pollen, a mix of both pollens, and pure blue hubbard pollen) and pollen amount (low, medium, high, and saturating applications) on (A) and (B) number of seeds per fruit and (C) and (D) weights per seed in butternut squash (C. moschata). Least significant means $( \pm \mathrm{SE})$ with a common letter are not significantly different $(P \leq 0.05)$ using Tukey's honestly significant difference test.

We also note that in the field, the congener $C$ pepo (pumpkin) produced an average of only 3.4 and 5.4 female flowers per year across a 2-year study (Stapleton et al., 2000), and potted butternut in the greenhouse produced $4.4+0.52$ female flowers over a 3-month period ( $\mathrm{n}=15$; Hladun, unpublished data). Thus, low female flower and fruit production is not unusual. Fruits were collected on 5 Aug. 2005. Of 240 butternut plants, 123 plants had at least one female flower treated; 39 of these plants produced one fruit and three plants produced two fruits. The responses measured were fruit set (fruit or aborted), fruit fresh weight, seed number, proportion developed seeds, and dry weight per seed.

Data analysis. Two-way multivariate analyses of variance (MANOVAs) and subsequent univariate analyses of variance (ANOVA) using SAS (2003; SAS Institute, Cary, NC) were used to determine the effects of pollen composition, pollen amount, and their interaction on butternut squash fruit and seed production. All data were averaged within plant to use plant as the unit of replication. Logistic regression was used to predict the probability of fruit set, including the continuous variable pollination date as a covariate. Because fruit set was relatively rare, plants that set fruit in either flower were counted as having fruit. Although fruits have an inhibitory effect on subsequent fruit production in the congener C. pepo (Stephenson et al., 1988), in our study, only three plants produced multiple fruits. Removing these plants did not change our results, and we report results including all plants that produced fruit.

\section{Results}

Pollen composition. Pollen composition affected butternut reproduction (MANOVA, $P<0.0001)$, largely through seed production. Butternut pollen and mixed pollen produced, respectively, $53 \%$ and $38 \%$ more seeds and $75 \%$ and $83 \%$ higher seed weights than blue hubbard pollen (ANOVA, seed number: $P<$ 0.006 ; seed weight: $P<0.0001$; Fig. $1 \mathrm{~A}, \mathrm{C}$ ). Pollen composition did not affect fruit weight or the proportion of developed seeds per fruit (ANOVA, $P>0.13$ for both) and did not affect fruit set [logistic regression, $P=0.57$; butternut pollen: 16 of 48 plants produced fruit (33\%), mixed pollen: 14 of $33(42.4 \%)$, blue hubbard pollen: 11 of 42 (26.2\%)].

Pollen amount. Pollen amount affected butternut reproduction (MANOVA, $P<$ 0.0001 ), again driven by seed production. Saturating amounts of pollen produced two to six times more seeds than lower pollen amounts (ANOVA, $P<0.0001$, Fig. 1B). Pollen amount did not affect fruit weight, weight per seed (Fig. 1D), or the proportion of developed seeds per fruit (ANOVA, $P>$ 0.10 for all). Pollen amount had a marginally significant effect on fruit set with the lowest pollen amount producing half as many fruit as the other treatments [logistic regression, $P=0.08$; low: six of 34 plants produced fruit 
(17.6\%), medium: 11 of 24 (45.8\%), high: 10 of 29 (34.5\%), saturation: 14 of $36(38.9 \%)$ ].

Interaction between pollen composition and pollen amount. Pollen amount and composition had additive effects on butternut reproduction (MANOVA, interaction term: $P=0.93$ ).

Pollination date. Plants pollinated later in the season were significantly less likely to produce fruit (logistic regression, $P<0.0001$ ).

\section{Discussion}

The primary goal of this study was to determine if blue hubbard as a PTC could reduce butternut squash yield through heterospecific pollen deposition. Perimeter trap crop design can encourage pollinator-mediated pollen flow between main crop and PTC, especially if pollinators move between congeneric crops as squash bees do. This study found that blue hubbard pollen can reduce butternut seed numbers and weight, but not fruit weight. Our results indicate some incompatibility between the two cucurbit species, as was found previously (Whitaker and Bemis, 1964). However, mixed blue hubbard and butternut pollen did not significantly reduce seed or fruit set, indicating that blue hubbard pollen did not interfere with conspecific ovule fertilization. In the field, PTC design requires far fewer PTC plants than main crop plants, and pollen deposition in the main crop would likely be primarily conspecific. Thus, pollen transfer from blue hubbard to butternut squash should not reduce yield provided that butternut squash pollen is also deposited on stigmas.

Another goal of this study was to determine the pollen requirements for full fruit and seed production in butternut squash. Saturating amounts of pollen produced substantially more seeds than the three lower treatments, indicating that butternut squash flowers required more than 654 pollen grains, or three visits from a squash bee or honeybee (Tepedino, 1981), to achieve maximum seed set. Fruit set was halved in the lowest pollen treatment compared with higher pollen amounts, although this effect was only marginally significant. This result is consistent with studies on several other cucurbit crops, which require multiple pollinator visits to achieve full fruit set (Adlerz, 1966; Kremen et al., 2002; Stanghellini et al., 1997). Adequate pollinator visitation may be needed to maintain crop yield in butternut squash as has been found in other cucurbits such as cucumber (Gingras et al., 1999; Stanghellini et al., 1997), watermelon (Adlerz, 1966; Kremen et al., 2002; Stanghellini et al., 1997), zucchini (Stephenson, 1981; Stephenson et al., 1988; Winsor et al., 1987), and pumpkin (Walters and Taylor, 2006). Fruit set was relatively low in this study (42 of 123 plants produced fruit as compared with $50 \%$ and $75 \%$ fruit set in a field study with C. pepo; Stapleton et al., 2000). It seems unlikely that our pollen amounts contributed to the low fruit set, because all treatments but the lowest amount produced equivalent fruit set. Surprisingly, pollen composition did not affect fruit set, suggesting that heterospecific pollen is capable of initiating fruit development. Although pollinating more flowers per plant could have increased the numbers of fruits for analysis, concerns about the effect of initial fruit set on subsequent abortion would have made these data difficult to interpret (e.g., Stephenson et al., 1988). Flowers pollinated on later dates were more likely to abort, suggesting that high greenhouse temperatures later in the experiment or limiting resources as plants grew larger may have contributed to our low fruit set. Future research could assess the role of pollen amount on fruit set in field studies where resources and temperatures reflect conditions most relevant to growers.

In summary, our results suggest that pollen from blue hubbard as a PTC is unlikely to reduce yield in butternut squash as long as plants also receive conspecific pollen. However, pollen transfer may affect ecological parameters such as seed number and quality. Using blue hubbard as a PTC for butternut squash should thus provide growers with a valuable method for reducing reliance on pesticides without loss of yield as a result of heterospecific pollen transfer.

\section{Literature Cited}

Adlerz, W.C. 1966. Honey bee visit numbers and watermelon pollination. J. Econ. Entomol. 59:28-30.

Andersen, J.F. and R.L. Metcalf. 1987. Factors influencing distribution of Diabrotica spp. in blossoms of cultivated Cucurbita spp. J. Chem. Ecol. 13:681-699.

Boucher, T.J. and R. Durgy. 2004. Demonstrating a perimeter trap crop approach to pest management on summer squash in New England. J. Ext. 42:1-6.

Fronk, W.D. and J.A. Slater. 1956. Insect fauna of cucurbit flowers. J. Kans. Entomol. Soc. 29:141-145.

Gingras, D., J. Gingras, and D. De Oliveira. 1999. Visits of honeybees (Hymenoptera: Apidae) and their effects on cucumber yields in the field. J. Econ. Entomol. 92:435-438.

Heinrich, B. 1981. The energetics of pollination. Ann. Miss. Botanical Garden 68:370-378.

Hurd, P.D., E.G. Linsley, and T.W. Whitaker. 1971. Squash and gourd bees (Peponapis,
Xenoglossa) and origin of cultivated Cucurbita. Evolution Int. J. Org. Evolution 25:218234.

Kirkpatrick, K.J. and H.D. Wilson. 1988. Interspecific gene flow in Cucurbita: C. texana vs. C. pepo. Amer. J. Bot. 75:519-527.

Kremen, C., N.M. Williams, and R.W. Thorp. 2002. Crop pollination from native bees at risk from agricultural intensification. Proc. Natl. Acad. Sci. USA 99:1681216816.

McGrath, M.T. 2002. Attractiveness of cucurbit crop types to cucumber beetles and their susceptibility to bacterial wilt, p. 222-227. In: D.N. Maynard (ed.). Cucurbitaceae. ASHS Press, Alexandria, VA.

Robinson, R.W. and D.S. Decker-Walters. 1997. Cucurbits. CAB Intl., Wallingford, UK.

Shuler, R.E., T.H. Roulston, and G.E. Farris. 2005. Farming practices influence wild pollinator populations on squash and pumpkin. J. Econ. Entomol. 98:790-795.

Stanghellini, M.S., J.T. Ambrose, and J.R. Schultheis. 1997. The effects of honey bee and bumble bee pollination on fruit set and abortion of cucumber and watermelon. J. Apicultural Research 137:386-391.

Stapleton, S.C., H.C. Wien, and R.A. Morse. 2000. Flowering and fruit set of pumpkin cultivars under field conditions. HortScience 35:10741077.

Stephenson, A.G. 1981. Flower and fruit abortion: Proximate causes and ultimate functions. Annu. Rev. Ecol. Syst. 12:253-279.

Stephenson, A.G., B. Devlin, and J.B. Horton. 1988. The effects of seed number and prior fruit dominance on the pattern of fruit production in Cucurbita pepo (Zucchini squash). Ann. Bot. (Lond.) 62:653-661.

Tepedino, V.J. 1981. The pollination efficiency of the squash bee (Peponapis pruinosa) and the honey bee (Apis mellifera) on summer squash (Cucurbita pepo). J. Kans. Entomol. Soc. 54: 359-377.

Walters, S.A. and B.H. Taylor. 2006. Effects of honey bee pollination on pumpkin fruit and seed yield. HortScience 41:370373.

Waser, N.M. and M.L. Fugate. 1986. Pollen precedence and stigma closure: A mechanism of competition for pollination between Delphinium nelsonii and Ipomopsis aggregata. Oecologia 70:573-577.

Whitaker, T.W. and W.P. Bemis. 1964. Evolution in the genus Cucurbita. Evolution Int. J. Org. Evolution 18:553-559.

Whitaker, T.W. and G.W. Bohn. 1950. The taxonomy, genetics, production and uses of the cultivated species of Cucurbita. Econ. Bot. 4:52-81.

Whitaker, T.W. and G.N. Davis. 1962. The cucurbits: Botany, cultivation, and utilization. Leonard Hill Ltd, London, UK.

Winsor, J.A., L.E. Davis, and A.G. Stephenson. 1987. The relationship between pollen load and fruit maturation and the effect of pollen load on offspring vigor in Cucurbita pepo. Amer. Naturalist 129:643-656. 